\title{
Molecular Mechanism of Metal-Independent Decomposition of Organic Hydroperoxides by Halogenated Quinoid Carcinogens and the Potential Biological Implications
}

\author{
Chun-Hua Huang, ${ }^{\dagger, \S}$ Fu-Rong Ren, ${ }^{\dagger} \S$ Guo-Qiang Shan, ${ }^{\ddagger}$ Hao Qin, ${ }^{\dagger}$ Li Mao, ${ }^{\dagger}$ and Ben-Zhan Zhu ${ }^{*}{ }^{\dagger}$ \\ ${ }^{\dagger}$ State Key Laboratory of Environmental Chemistry and Ecotoxicology Research Center for Eco-Environmental Sciences, CAS, \\ Beijing 100085, China \\ ${ }^{\ddagger}$ Key Laboratory of Pollution Processes and Environmental Criteria, MOE, Nankai University, Tianjin 300071, China
}

ABSTRACT: Halogenated quinones (XQ) are a class of carcinogenic intermediates and newly identified chlorination disinfection byproducts in drinking water. Organic hydroperoxides $(\mathrm{ROOH})$ can be produced both by free radical reactions and enzymatic oxidation of polyunsaturated fatty acids. $\mathrm{ROOH}$ have been shown to decompose to alkoxyl radicals via catalysis by transition metal ions, which may initiate lipid peroxidation or transform further to the reactive aldehydes. However, it is not clear whether XQ react with $\mathrm{ROOH}$ in a similar manner to generate alkoxyl radicals metal-independently. By complementary applications of ESR spin-trapping, HPLC/high resolution mass spectrometric and other analytical methods, we found that 2,5-dichloro-1,4-benzoquinone (DCBQ) could significantly enhance the decomposition of a model $\mathrm{ROOH}$ tert-butylhydroperoxide, resulting in the formation of $t$-butoxyl radicals independent of transition metals. On the basis of the above findings, we detected

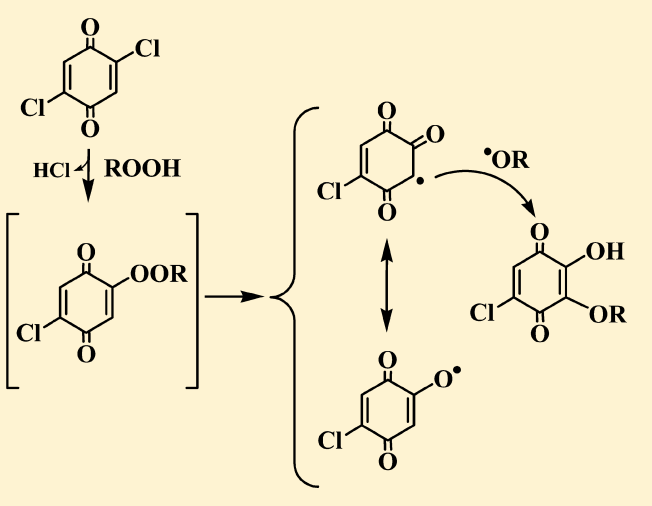
and identified, for the first time, an unprecedented C-centered quinone ketoxy radical. Then, we extended our study to the more physiologically relevant endogenous ROOH 13-hydroperoxy-9,11-octadecadienoic acid and found that DCBQ could also markedly enhance its decomposition to generate the reactive lipid alkyl radicals and the genotoxic 4-hydroxy-2-nonenal (HNE). Similar results were observed with other XQ. In summary, these findings demonstrated that XQ can facilitate $\mathrm{ROOH}$ decomposition to produce reactive alkoxyl, quinone ketoxy, lipid alkyl radicals, and genotoxic HNE via a novel metal-independent mechanism, which may explain partly their potential genotoxicity and carcinogenicity.

\section{CONTENTS}

1. Introduction

2. Metal-Independent $\mathrm{ROOH}$ Decomposition and $\mathrm{RO}{ }^{\bullet}$ Generation by $\mathrm{XQ}$

3. Characterization of a Novel Carbon-Centered Quinone Ketoxy Radical Intermediate

4. Unequivocal Identification of the Radical Form of the Ketoxy Radical Adduct

5. Metal-Independent Decomposition of Endogenous $\mathrm{ROOH}$ by $\mathrm{XQ}$

6. Conclusions and Future Research

Author Information

Corresponding Author

Author Contributions

Funding

Notes

831

832

834

834

835

836

836

836

836

836

836

Abbreviations

References

\section{INTRODUCTION}

Halogenated quinones (XQ) are a class of toxic intermediates that can initiate many harmful effects in vivo, such as acute hepatoxicity, nephrotoxicity, and carcinogenesis. ${ }^{1,2}$ Chlorinated 1,4-benzoquinones (such as tetrachloro- and 2,5-dichloro-1,4benzoquinone) are the major genotoxic and carcinogenic quinoid metabolites of the widely used pesticides chlorinated phenols (the wood preservative pentachlorophenol (PCP) and 2,4,5-trichlorophenol). PCP has been detected in at least $1 / 5$ National Priorities List sites recognized by the US EPA and classified by the IARC as a group $2 \mathrm{~B}$ environmental carcinogen. ${ }^{3}$ XQ have also been identified as toxic intermediates or products during the oxidation or destruction of halophenols and other polyhalogenated persistent organic pollutants (POPs). ${ }^{3-6}$ Recently, a dozen XQ were found to be new chlorination byproducts in disinfected drinking water and in swimming pool waters, ${ }^{7,8}$ and some were also identified in pulp and paper mill discharges. These XQwere found to cause damage to DNA and protein by both oxidation and adduct formation, ${ }^{1-6,9-11}$ and therefore, they are potentially carcinogenic.

Organic hydroperoxides ( $\mathrm{ROOH})$ can be produced both nonenzymatically and enzymatically. ${ }^{12,13} \mathrm{ROOH}$ have been shown to decompose to alkoxyl radicals $\left(\mathrm{RO}^{\bullet}\right)$ via transition metal catalysis, which may cause de novo lipid peroxidation or

Received: November 25, 2014

Published: March 19, 2015 
further transform to $\alpha, \beta$-unsaturated aldehydes that can react with and damage DNA, proteins, and lipids. ${ }^{12,13}$

$$
\mathrm{ROOH}+\mathrm{Me}^{(\mathrm{n}-1)+} \rightarrow \mathrm{RO}^{\bullet}+\mathrm{OH}^{-}+\mathrm{Me}^{\mathrm{n}+}
$$

We have shown recently that the hydroxyl radical and chemiluminescence can be produced during the decomposition of $\mathrm{H}_{2} \mathrm{O}_{2}$ by tetrachloro-1,4-benzoquinone (TCBQ) and other XQ (Figure 1) in a metal-independent manner and have proposed a<smiles>O=C1C(Cl)=C(Cl)C(=O)C(Cl)=C1Cl</smiles>

TCBQ<smiles>O=C1C=C(Cl)C(=O)C(Cl)=C1</smiles>

2,6-DCBQ<smiles>O=C1C=C(Cl)C(=O)C(Cl)=C1Cl</smiles>

$\operatorname{TrCBQ}$<smiles>O=C1C=CC(=O)C(Cl)C1</smiles>

2-CBQ<smiles>O=C1C=CC(=O)C(Cl)=C1Cl</smiles>

2,3-DCBQ<smiles>O=C1C(Br)=C(Br)C(=O)C(Br)=C1Br</smiles>

TBBQ<smiles>O=C1C=C(Cl)C(=O)C=C1Cl</smiles>

2,5-DCBQ<smiles>O=C1C(F)=C(F)C(=O)C(F)=C1F</smiles>

TFBQ
Figure 1. Chemical structures of the halogenated quinones.
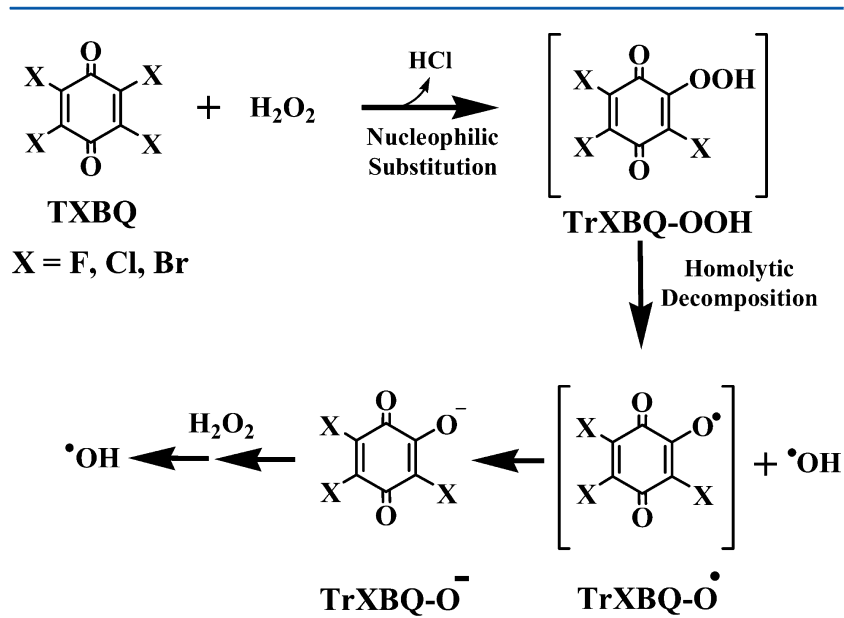

Figure 2. Proposed mechanism for ${ }^{\bullet} \mathrm{OH}$ production by tetrahalo-1,4benzoquinone ( $T X B Q, X=F, C l, B r$ ) and $\mathrm{H}_{2} \mathrm{O}_{2}$ : a nucleophilic reaction may take place between TXBQ and $\mathrm{H}_{2} \mathrm{O}_{2}$, forming a trihalohydroperoxyl-1,4-benzoquinone (TrXBQ-OOH) intermediate, which can decompose homolytically to produce the ${ }^{\circ} \mathrm{OH}$ and the trihalo-hydroxy1,4-benzoquinone radical ( $\operatorname{TrXBQ}-\mathrm{O}^{\bullet}$ ). Reproduced with permission from ref 16. Copyright 2007 National Academy of Sciences, U.S.A.

novel nucleophilic substitution coupled with homolytical decomposition mechanism (Figure 2). ${ }^{14-18}$ Potent oxidative DNA damage (8-oxodeoxyguanosine formation) and methyl oxidation of 5-methyl-2'-deoxycytidine by XQ and $\mathrm{H}_{2} \mathrm{O}_{2}$ were observed via a metal-independent hydroxyl radical mechanism. ${ }^{19-21}$ However, it is unclear whether XQ interact analogously with $\mathrm{ROOH}$ to transition-metal-independently generate $\mathrm{RO}^{\bullet}$.

Therefore, in a recent study we tried to address these questions. (i) Can the ROOH decomposition be facilitated by XQ to generate $\mathrm{RO}^{\bullet}$ ? (ii) If so, is $\mathrm{RO}^{\bullet}$ generation metal-dependent? (iii) What is the underlying molecular mechanism?

\section{METAL-INDEPENDENT ROOH DECOMPOSITION AND RO• GENERATION BY XQ}

Using 2,5-dichloro-1,4-benzoquinone (DCBQ) as a model XQ and tert-butylhydroperoxide $(t-\mathrm{BuOOH})$ as a model $\mathrm{ROOH}$, we found that DCBQ could markedly enhance $t$ - $\mathrm{BuOOH}$ decomposition and the generation of the DMPO adducts with $t$-butoxyl radicals $\left(t-\mathrm{BuO}^{\bullet}\right)$ and methyl radicals $\left({ }^{\bullet} \mathrm{CH}_{3}\right)$ (Figure 3$){ }^{22}$ It is worth noting that a small radical signal was also detected in both DCBQ and 2,6-dichloro-1,4-benzoquinone (2,6-DCBQ) systems but could not be observed in $\mathrm{Fe}$ and other XQ systems (for further identification of this radical adduct, see section 3 below). In contrast, incubation of either compound alone did not lead to $t$ - $\mathrm{BuO}^{\bullet}$ or ${ }^{\bullet} \mathrm{CH}_{3}$ generation (Figure 3). The middle triplet signal for DCBQ alone was found to be the 2,5-dichloro-semiquinone anion radical ( $\mathrm{DCSQ}^{-}$). Together, the above findings indicate that $\mathrm{DCBQ}$ can facilitate $t$-BuOOH decomposition and the generation of $t-\mathrm{BuO}^{\bullet}$ and ${ }^{\bullet} \mathrm{CH}_{3}$.

Redox-active transition metals, especially $\mathrm{Fe}$ and $\mathrm{Cu}$, have been found to mediate $t-\mathrm{BuO}^{\bullet}$ and ${ }^{\circ} \mathrm{CH}_{3}$ generation from $t$-BuOOH. ${ }^{12,13}$ Therefore, several specific metal chelators for $\mathrm{Fe}$ and $\mathrm{Cu}$ were employed to study the potential role of trace amounts of such metal ions. ${ }^{12,23-25}$ Neither $\mathrm{DMPO} / t-\mathrm{BuO}{ }^{\bullet}$ nor $\mathrm{DMPO} /{ }^{\bullet} \mathrm{CH}_{3}$ signal was affected by the addition of several $\mathrm{Fe}(\mathrm{II})$-specific or $\mathrm{Cu}(\mathrm{I})$-specific chelators. These findings clearly indicate that transition metal ions contaminated in the system are not responsible for radical formation.

The metal-independent $t$ - $\mathrm{BuO}{ }^{\bullet}$ and ${ }^{\bullet} \mathrm{CH}_{3}$ generation was not restricted to $\mathrm{DCBQ}$ and $t-\mathrm{BuOOH}$ but was also found when DCBQ was replaced by other XQ. However, no $t-\mathrm{BuO}^{\bullet}$ and ${ }^{\circ} \mathrm{CH}_{3}$ generation was observed from $t-\mathrm{BuOOH}$ and the non-XQ, or the methyl-substituted quinones.

It should be noted that $\mathrm{DCSQ}^{\bullet-}$ was detected once DCBQ was added to the phosphate buffer. Water was suggested as the major source of the electrons to reduce DCBQ via hydrolysis of $\mathrm{DCBQ}^{26}$ The $\mathrm{DCSQ}^{\bullet-}$ signal was found to be remarkably reduced after $t$ - $\mathrm{BuOOH}$ addition, with concurrent $t-\mathrm{BuO}^{\bullet}$ generation (c.f. Figure 3). These results indicate that $\mathrm{DCSQ}^{\bullet-}$ may directly reduce $t-\mathrm{BuOOH}$ to $t-\mathrm{BuO}^{\bullet}$ (reaction 2 ), which is similar to the $\mathrm{Fe}(\mathrm{II})$-catalyzed $t-\mathrm{BuOOH}$ decomposition to $t-\mathrm{BuO}^{\bullet}$ (reaction 3):

$$
t-\mathrm{BuOOH}+\mathrm{DCSQ}^{\bullet-} \rightarrow t-\mathrm{BuO}^{\bullet}+\mathrm{OH}^{-}+\mathrm{DCBQ}
$$

$$
t-\mathrm{BuOOH}+\mathrm{Fe}^{2+} \rightarrow t-\mathrm{BuO}^{\bullet}+\mathrm{OH}^{-}+\mathrm{Fe}^{3+}
$$

If the above mechanism were true, then the generation of $t$ - $\mathrm{BuO}^{\bullet}$ from $t$-BuOOH/DCBQ should be dependent on $\mathrm{DCSQ}^{\bullet-}$ concentration, i.e., the higher the concentration, the more $t$ - $\mathrm{BuO}^{\bullet}$ will be generated; and the main product of this reaction should be DCBQ. However, no DMPO $/ t-\mathrm{BuO}^{\bullet}$ was observed from the reduced form of $\mathrm{DCBQ}$ 2,5-dichlorohydroquinone (DCHQ), and $t$ - $\mathrm{BuOOH}$, although high $\mathrm{DCSQ}^{\bullet-}$ concentrations were generated during DCHQ auto-oxidation (Figure 3). Interestingly, $\mathrm{DMPO} / \mathrm{t}-\mathrm{BuO}^{\bullet}$ could be observed again when $\mathrm{DCHQ}$ was quickly transformed by myeloperoxidase to DCBQ (Figure 3). In addition, $\mathrm{DMPO} / t$ - $\mathrm{BuO}^{\bullet}$ formation was observed to be directly dependent on DCBQ concentration. These findings indicate that $\mathrm{DCBQ}$, rather than $\mathrm{DCSQ}^{\bullet-}$, may be critical for $t-\mathrm{BuO}^{\bullet}$ generation.

Electrospray ionization quadrupole time-of-flight mass spectrometry (ESI-Q-TOF-MS) was then employed to characterize the final reaction product for $\mathrm{DCBQ} / t-\mathrm{BuOOH}$, which was identified as the ionic form of 2-chloro-5-hydroxy-1,4-benzoquinone $(\mathrm{CBQ}-\mathrm{OH})$. Therefore, the metal-independent $t$ - $\mathrm{BuO}^{\bullet}$ generation by $\mathrm{DCBQ} / t-\mathrm{BuOOH}$ seems not to occur via a $\mathrm{DCSQ}^{\bullet-}$ mediated Fenton-like reaction. On the basis of the above findings, we proposed a novel mechanism for DCBQ-enhanced 


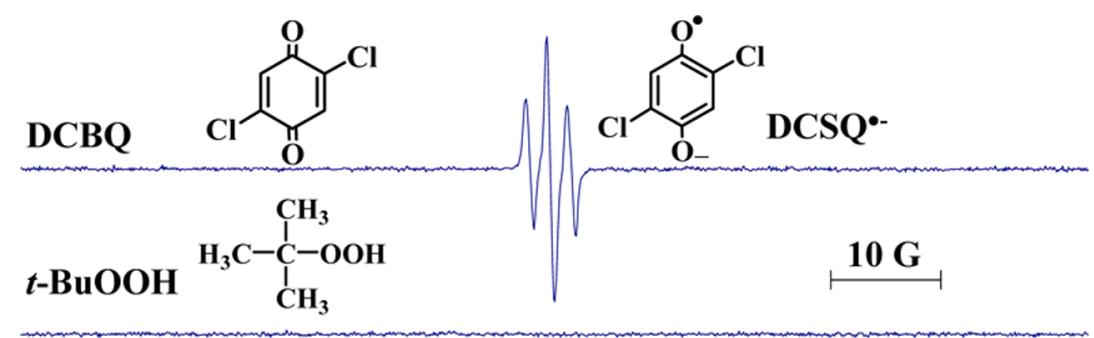

\section{$\mathrm{DCBQ} / t-\mathrm{BuOOH}$}
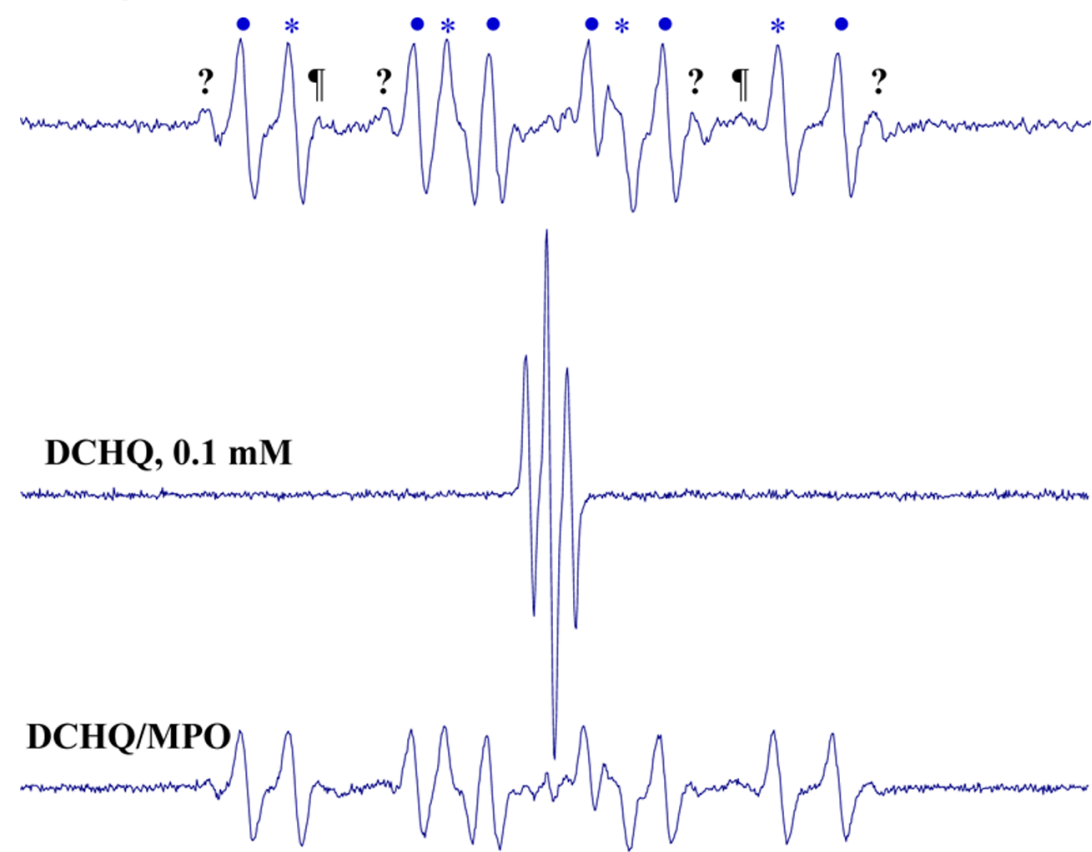

* DMPO/t-BuO $\bullet \mathrm{DMPO}^{\circ} \mathrm{CH}_{3}$ ๆ $\mathrm{DMPO} / \bullet \mathrm{OCH}_{3} ?$ Unidentified

Figure 3. Metal-independent decomposition of $t-\mathrm{BuOOH}$ and formation of alkoxyl radicals by 2,5-dichloro-1,4-benzoquinone (DCBQ) or its reduced form 2,5-dichlorohydroquinone (DCHQ) in the absence or presence of myeloperoxidase. Reproduced with permission from ref 22 . Copyright 2007 National Academy of Sciences, U.S.A.

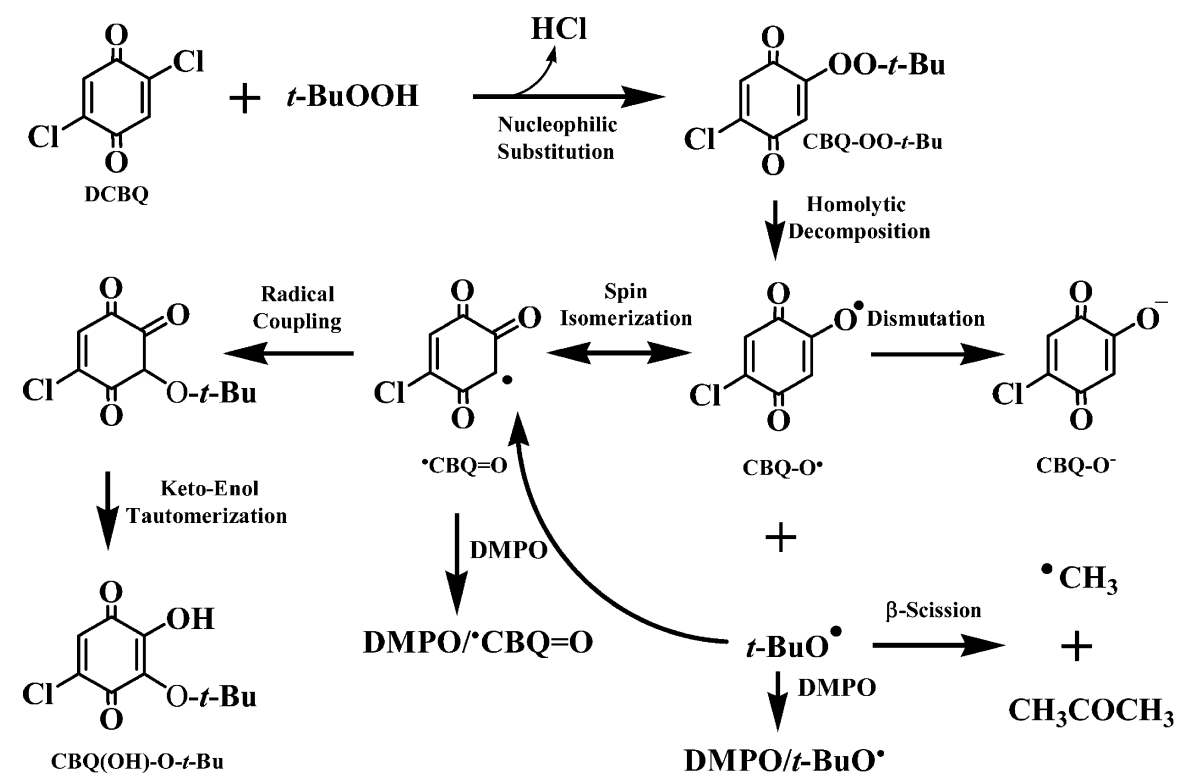

Figure 4. Proposed mechanism for DCBQ-mediated $t$-BuOOH decomposition and formation of the novel carbon-centered quinone ketoxy radical and the final reaction product $\mathrm{CBQ}(\mathrm{OH})-\mathrm{O}-\mathrm{t}$-Bu. Reproduced with permission from ref 27. Copyright 2009 National Academy of Sciences, U.S.A. 
$t$-BuOOH decomposition and $t$ - $\mathrm{BuO}{ }^{\bullet}$ and ${ }^{\circ} \mathrm{CH}_{3}$ generation: $t$-BuOOH may first attack DCBQ via nucleophilic substitution, generating an unstable chloroquinone/peroxide CBQ-OO- $t$ - Bu, which decomposes homolytically to forn $t$ - $\mathrm{BuO}^{\bullet}$ and an oxygencentered quinone enoxy radical $\left(\mathrm{CBQ}-\mathrm{O}^{\bullet}\right)$ (see Figure 4$)^{22}$

\section{CHARACTERIZATION OF A NOVEL CARBON-CENTERED QUINONE KETOXY RADICAL INTERMEDIATE}

In the above studies, we found that XQ could enhance $\mathrm{ROOH}$ decomposition and alkoxyl radical generation via a metalindependent mechanism. ${ }^{22}$ However, both the major reaction products and the suggested chloroquinone/peroxide intermediate $\mathrm{CBQ}-\mathrm{OO}-\mathrm{t}-\mathrm{Bu}$ and enoxy radical $\mathrm{CBQ}^{-} \mathrm{O}^{\bullet}$ were unequivocally charaterized.

Therefore, in the following study a semipreparative HPLC method was employed in order to swiftly obtain the hypothesized reaction intermediate and major products. ${ }^{27}$ As expected, one of the major products was found to be CBQ-OH. Another product was first assumed to be the CBQ-OO- $t$-Bu intermediate (MW 230) since this product was identified by ESI-Q-TOF-MS with $1-\mathrm{Cl}$ isotope clusters at $m / z 229$, and the MS/MS study found that it could be fragmented easily to form a peak at $m / z$ 172. However, further spectral investigations suggested that it was not the intermediate CBQ-OO- $t$-Bu since it is a rather stable compound which may contain an $\mathrm{OH}$-group. Finally, it was identified, unexpectedly, as the rearranged isomer of the intermediate CBQ-OO- $t$-Bu, 2-hydroxy-3-t-butoxy-5-chloro-1,4benzoquinone $(\mathrm{CBQ}(\mathrm{OH})-\mathrm{O}-\mathrm{t}-\mathrm{Bu})$ (for its chemical structure, see Figure 4).

Two new issues arise from this unexpected result: (1) Is the new product $\mathrm{CBQ}(\mathrm{OH})-\mathrm{O}-\mathrm{t}$-Bu directly resulting from the unstable CBQ-OO-t-Bu, and (2) if so, what is the exact mechanism? To address these issues, a new hypothesis was proposed: the unstable CBQ-OO-t-Bu may undergo homolytical decomposition, resulting in $t-\mathrm{BuO}^{\bullet}$ and $\mathrm{CBQ}-\mathrm{O}^{\bullet}$ generation; The O-centered $\mathrm{CBQ}-\mathrm{O}^{\bullet}$ might be readily isomerized to its corresponding more stable $\mathrm{C}$-centered ketoxy radical $\left({ }^{\bullet} \mathrm{CBQ}=\mathrm{O}\right)$. The coupling of ${ }^{\circ} \mathrm{CBQ}=\mathrm{O}$ with $t$ - $\mathrm{BuO}^{\bullet}$ should generate $\mathrm{CBQ}(\mathrm{OH})-\mathrm{O}-\mathrm{t}$ - $\mathrm{Bu}$ (see Figure 4). If the above assumption were right, DMPO should inhibit $\mathrm{CBQ}(\mathrm{OH})-\mathrm{O}-\mathrm{t}-\mathrm{Bu}$ formation since it can compete with ${ }^{\circ} \mathrm{CBQ}=\mathrm{O}$ to trap $t-\mathrm{BuO}^{\bullet}$. We found that this was exactly the case.

Interestingly and unexpectedly, a new peak was detected from $\mathrm{DCBQ} / t-\mathrm{BuOOH}$ with DMPO, which was identified by ESI-QTOF-MS with $1-\mathrm{Cl}$ isotope peak clusters at $\mathrm{m} / z$ 268. These findings suggest that it might be a DMPO adduct with either a $\mathrm{CBQ}-\mathrm{O}^{\bullet}$ or $\mathrm{a}^{\bullet} \mathrm{CBQ}=\mathrm{O}$ radical (simply referred to here as DMPO-157). Fourier transform ion cyclotron resonance (FTICR) mass spectrometry was then used to obtain more accurate information on DMPO-157. ${ }^{28,29}$ DMPO-157 was identified by FTICR/MS with $1-\mathrm{Cl}$ isotope peak clusters at $\mathrm{m} / \mathrm{z}$ 268.0383, corresponding to the nitrone form of DMPO- 157 . When $t$ - $\mathrm{BuOOH}$ was substituted by $\mathrm{H}_{2} \mathrm{O}_{2}$ and cumene hydroperoxide, the same DMPO-157 was detected.

In our earlier DMPO spin-trapping study on DCBQ/ $t$-BuOOH, a minor DMPO adduct with weak ESR signals was also detected but not identified yet (see Figure 3$).{ }^{22}$ With the newly obtained FTICR/MS results, we speculated that this unknown radical signal might be the DMPO adduct with either enoxy or its ketoxy radical. However, due to the strong disturbance by the ESR signals from other DMPO radical adducts, only a weak 4-line ESR signal with equal intensity could be detected.
Therefore, it is unclear just from these findings whether the DMPO trapped radical is an $\mathrm{O}$ - or a C-centered quinone radical.

To avoid the strong interference of other ESR signals of DMPO radical adducts and get a better DMPO-157 ESR signal, we investigated DCBQ $/ \mathrm{H}_{2} \mathrm{O}_{2}$ with DMPO. Beside the expected $\mathrm{DMPO} /{ }^{\circ} \mathrm{OH}$, we also detected 6 -line ESR spectra with the same intensity $\left(a^{\mathrm{H}}=28.8 \mathrm{G} ; a^{\mathrm{N}}=17.0 \mathrm{G} ; a^{\mathrm{N}} / a^{\mathrm{H}}=0.59\right)($ Figure 5),

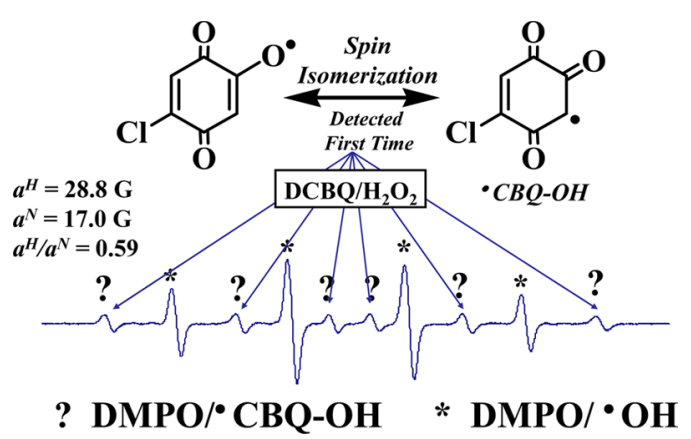

Figure 5. DMPO nitroxide adduct with the carbon-centered quinone ketoxy radical. Reproduced with permission from ref 27. Copyright 2009 National Academy of Sciences, U.S.A.

which are characteristic of the spin-trapping of a $\mathrm{C}$-centered ${ }^{\bullet} \mathrm{CBQ}=\mathrm{O}$, rather than an $\mathrm{O}$-centered $\mathrm{CBQ}-\mathrm{O}^{\bullet}{ }^{30}$ To the best of our knowledge, this is the first report that a $\mathrm{C}$-centered ketoxy radical was characterized by the complementary application of ESR spin trapping, NMR, and FTICR/MS methods.

\section{UNEQUIVOCAL IDENTIFICATION OF THE RADICAL FORM OF THE KETOXY RADICAL ADDUCT}

In the above study, a new ketoxy radical ( $\left.{ }^{\circ} \mathrm{CBQ}-\mathrm{OH}, \mathrm{MW}: 157\right)$ adduct with DMPO (DMPO-157) was observed for the DCBQ/ $t$-BuOOH system. ${ }^{27}$ However, although we can detect its nitroxide radical form DMPO-157 by ESR, we cannot directly observe the radical form by MS, only its corresponding nitrone form. Similarly, only the ESR-silent DMPO-157 nitrone adduct can be isolated by HPLC but not its corresponding ESR-active nitroxide radical form. ${ }^{27}$ In summary, we were unable to get the clean DMPO-157 nitroxide radical adduct and thus observe its pure 6-line ESR spectra with no disturbance of other simultaneously produced radicals. It might be due to the following reasons: either the DMPO-157 nitroxide radical adduct was too reactive to further oxidize to its ESR-silent nitrone form during HPLC analysis, or the radical adduct concentration was too low to be measured by ESR.

Therefore, in a recent study, ${ }^{31}$ we tried to address these issues: Can we find a spin-trap which can produce a stable enough nitroxide radical adduct with the ketoxy radical? If so, can we characterize the radical form by MS directly, and can it be isolated and purified by semipreparative HPLC, then its pure ESR signal detected?

It has been found that certain radical adducts with 5-tbutoxycarbonyl 5-methyl-1-pyrroline $\mathrm{N}$-oxide (BMPO), a spintrap possessing analogous DMPO structure, were much stable than their corresponding DMPO adducts. ${ }^{32}$ Thus, BMPO was selected for our study. To our surprise, the half-life for the $\mathrm{BMPO} /{ }^{\circ} \mathrm{CBQ}-\mathrm{OH}$ radical adduct was found to be around $5 \mathrm{~h}$ (only $15 \mathrm{~min}$ for $\mathrm{DMPO} /{ }^{\circ} \mathrm{CBQ}-\mathrm{OH}$ ).

The generation of the $\mathrm{BMPO} /$ ketoxy radical derived nitroxide and nitrone adducts (here generally referred to as BMPO-157) by $\mathrm{DCBQ} / t-\mathrm{BuOOH}$ with $\mathrm{BMPO}$ were investigated preliminarily 
<smiles>C[C@H]1C(=O)C=C(Cl)C1=O</smiles><smiles></smiles><smiles>CCC1(C)CCCN1O</smiles><smiles></smiles>

BMPO/CBQ-OH Nitrone $m / z, 354$<smiles>Cl[C@H]1C[C@H]2O[C@@H]1[C@H]2Cl</smiles><smiles>CC1=CC(=O)C(=O)C2CN=CCC1C2</smiles>
H ${ }_{\mathrm{H}} \mathrm{C}_{\mathrm{O}}^{-\mathrm{O}-t \mathrm{Bu}}$ One-Eleçtron ВMPOO/CBQ-OH Nitroxide $m / z 355$
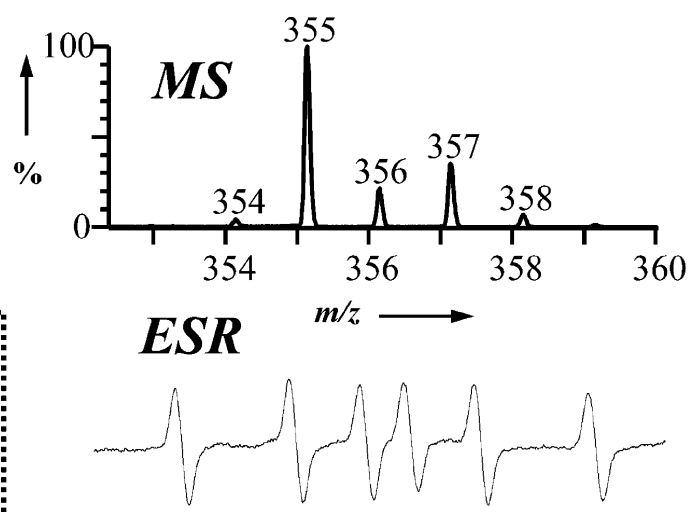

BMPO/•CBQ-OH: $\mathrm{a}^{\mathrm{H}}=26.5 \mathrm{G}, \mathrm{a}^{\mathrm{N}}=16.28 \mathrm{G}$

Figure 6. Purification and unequivocal characterization of the radical form of the BMPO/ketoxy radical adduct. Reproduced with permission from ref 31. Copyright 2013 The Royal Society of Chemistry.

by ESI-Q-TOF-MS. As expected, the 1-Cl isotope clusters at $m / z$ 354 , the nitrone form of BMPO-157, were detected by MS. By serendipity, a new peak with $1-\mathrm{Cl}$ isotope clusters at $m / z 355$ was also detected concurrently, which might be the nitroxide radical form of BMPO-157 on the basis of theoretical calculations.

For further confirmation, we tried to isolate the two distinct forms of BMPO-157 by HPLC. Because the nitroxide radical form of BMPO-157 is sensitive to acidic medium, we used a neutral mobile phase instead. Two new peaks with different retention times were detected. One of them was found to be the nitrone form of BMPO-157 $(\mathrm{m} / z$ 354), while the other was its corresponding nitroxide radical form $(\mathrm{m} / z$ 355) (Figure 6), which were further confirmed by MS/MS. These findings clearly indicated that the two forms of BMPO-157 could be characterized by HPLC-MS and that the peak with $\mathrm{m} / z$ at 355 should be the nitroxide radical form of BMPO-157, which was further confirmed to be the case by FTICR/MS and theoretical calculations.

To further substantiate whether the peak at $m / z 355$ is the radical adduct $\mathrm{BMPO} /{ }^{\circ} \mathrm{CBQ}-\mathrm{OH}$, it is imperative to get the pure fraction with the peak at $m / z 355$ with ESR examination. As expected, a pure 6-line ESR spectrum could be detected with the isolated fraction by semipreparative HPLC, corresponding to the six equal ESR peaks from $\mathrm{DCBQ} / \mathrm{t}$-BuOOH with $\mathrm{BMPO}$ $\left(a^{\mathrm{H}}=25.9 ; a^{\mathrm{N}}=16.04 ;\right.$ and $\left.a^{\mathrm{N}} / a^{\mathrm{H}}=0.62\right)($ Figure 6).

The above findings may also have important biological relevance. Our results indicate that these XQ may interact with hydroperoxides and exert toxic effects not only via facilitated generation of alkoxyl/hydroxyl radicals but also via the production of ketoxy radicals which may have direct interaction with DNA, protein, and lipids.

Recently, $\mathrm{H}_{2} \mathrm{O}_{2}$ has been often used as an oxidizing agent for the destruction of chlorinated phenols and other persistent organic substances. ${ }^{4-6}$ In these environmentally friendly systems, millimolar levels of $\mathrm{H}_{2} \mathrm{O}_{2}$ have been often employed. One recent research demonstrated that 2,6-DCBQ could be observed quickly and then further transformed to other products during advanced oxidation of 2,4,6-trichlorophenol (2,4,6-TCP) by $\mathrm{H}_{2} \mathrm{O}_{2}$ and iron complexes. ${ }^{6}$ Another research found that $\mathrm{H}_{2} \mathrm{O}_{2}$ could enhance the TCBQ hydrolysis rate hundreds of times. ${ }^{26} \mathrm{It}$ was pointed out that the $\mathrm{H}_{2} \mathrm{O}_{2}$-induced $\mathrm{XQ}$ decomposition mechanism may be critical in systems where $\mathrm{H}_{2} \mathrm{O}_{2}$ is either employed or generated. However, the exact molecular mechanisms underlying such further changes still remain unclear.
Our new discoveries may provide a new perspective to better elucidate such decomposition pathways during advanced oxidation treatment for wastewater or remediation processes in which XQ are produced.

\section{METAL-INDEPENDENT DECOMPOSITION OF ENDOGENOUS ROOH BY XQ}

Lipid peroxidation (LPO) has been extensively investigated for many years. ${ }^{33-36}$ 13-Hydroperoxy-9,11-octadecadienoic acid (13-HPODE) is one of the most well-known endogenous ROOH. ${ }^{33-36}$ In the presence of Fe(II), 13-HPODE could first produce the lipid alkoxyl radical, which will further generate reactive lipid alkyl radicals and genotoxic aldehydes like 4-hydroxy-2-nonenal (HNE). ${ }^{37-40}$ We have shown above that alkoxyl/ketoxy radicals can be generated during the $t$ - $\mathrm{BuOOH}$ decomposition by XQ metal-independently. ${ }^{22,27,31}$

Since 13-HPODE is a secondary $\mathrm{ROOH}$ possessing a long chain, while $t-\mathrm{BuOOH}$ is a tertiary $\mathrm{ROOH}$ with only a short $t$-butyl group, we presumed that the interactions between DCBQ and the two ROOH should not only have similarities but also differences. Therefore, in a recent research, ${ }^{41}$ we tried to address these issues: (1) Could DCBQ and other XQ facilitate 13-HPODE breakdown and production of the reactive radical intermediates and the genotoxic aldehydes metal-independently? (2) If so, what are the differences (i) between the breakdown of 13-HPODE and $t$-BuOOH by DCBQ and (ii) between DCBQ- and Fe(II)-induced 13-HPODE decomposition? (3) What is the underlying molecular mechanism?

With POBN as the spin-trap, the characteristic POBN adducts could be generated only when both DCBQ and 13-HPODE were present simultaneously. To differentiate the different POBN adducts formed, HPLC/MS was employed to separate and identify them. Selective reaction monitoring (SRM) mode was used for analysis due to the low levels of spin-trapped radical adducts formed. The following three POBN/radical (pentyl, 7-carboxyheptyl, 1-(7-carboxyheptyl)-4,5-epoxy-2-decenyl, or 1-(1,2-epoxyheptyl)-10-carboxy-2-decenyl radical) adducts were observed in DCBQ/13-HPODE with POBN.

As expected, $\mathrm{CBQ}-\mathrm{OH}$ and a quinone-lipid alkoxyl conjugate $\mathrm{CBQ}(\mathrm{OH})-13-\mathrm{O}-\mathrm{L}$ were found as two major reaction products for DCBQ/13-HPODE. Serendipitously, a new product CBQ(OH)-9-O-LO was also detected. HNE was analyzed by GC/MS after derivatizations. We found that DCBQ could indeed enhance 


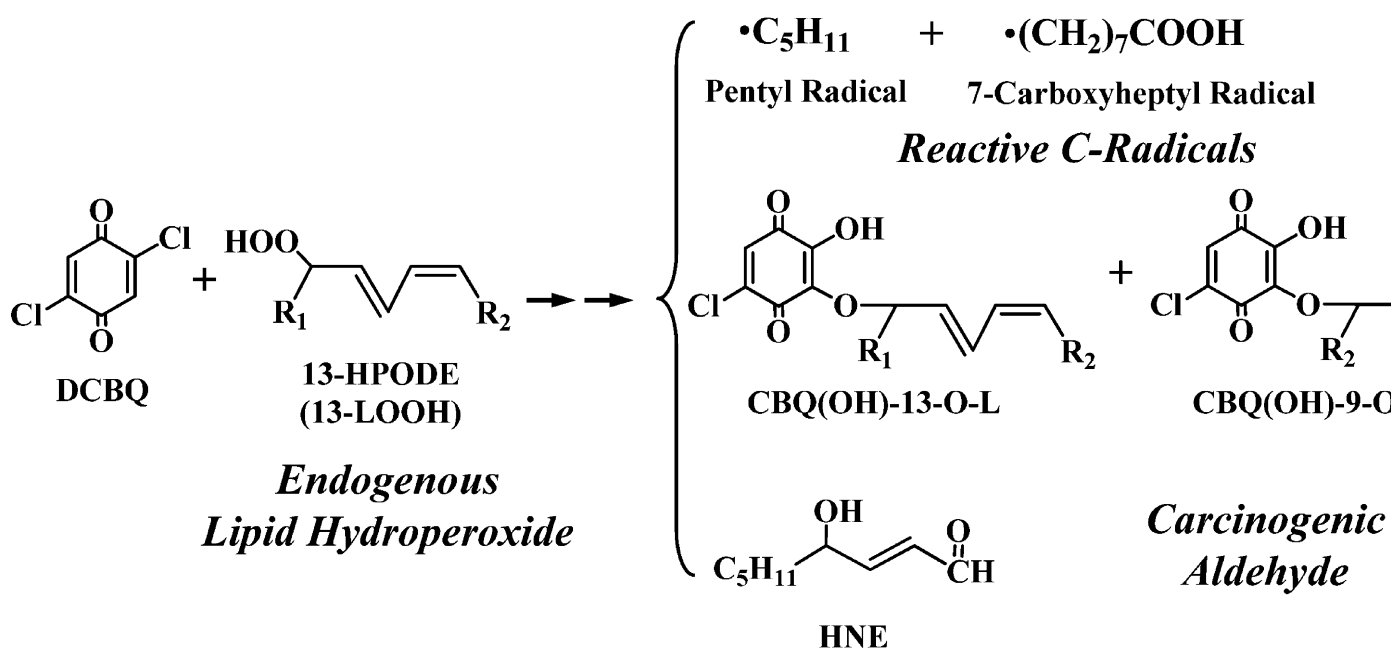

Figure 7. Metal-independent decomposition of endogenous lipid hydroperoxide 13-HPODE by halogenated quinoid carcinogens. Reprinted with permission from ref 41. Copyright 2013 Elsevier.

HNE formation. Analogous results were obtained when DCBQ was replaced by other XQ.

Putting the above findings together, we suggest the following molecular mechanism for DCBQ-induced 13-HPODE decomposition (Figure 7): 13-HPODE (13-LOOH) may first attack DCBQ via nucleophilic substitution, generating a chloroquinone/peroxide intermediate CBQ-13-OOL, which may form 13- $\mathrm{LO}^{\bullet}$ and $\mathrm{CBQ}^{\circ} \mathrm{O}^{\bullet}$ via homolytical decomposition. CBQ-O ${ }^{\bullet}$ then either dismutates to produce $\mathrm{CBQ}-\mathrm{OH}$ or isomerizes to produce ${ }^{\bullet} \mathrm{CBQ}=\mathrm{O}$, which then coupled with $13-\mathrm{LO}^{\bullet}$ to form $\mathrm{CBQ}(\mathrm{OH})-13-\mathrm{O}-\mathrm{L}$. The $13-\mathrm{LO}^{\bullet}$ could either break down to pentyl radical via $\beta$-scission or isomerize to produce the $\mathrm{C}$-centered $\mathrm{OL}^{\bullet}$, which then via oxygen addition generates a new $\mathrm{ROOH}$ (9-OLOOH). 9-OLOOH then may interact with DCBQ to produce $9-\mathrm{OLO}^{\bullet}$, which either coupled with ${ }^{\bullet} \mathrm{CBQ}=\mathrm{O}$ to form $\mathrm{CBQ}(\mathrm{OH})-9-\mathrm{O}-\mathrm{LO}$ or decomposed to the 7-carboxyheptyl radical via $\beta$-scission.

\section{CONCLUSIONS AND FUTURE RESEARCH}

The above finding represents an unusual pathway for alkoxyl/ ketoxy radical and/or HNE production not involving redoxactive metals and may explain, at least in part, the potential carcinogenicity of not only PCP but also other widely used halogenated aromatic carcinogens (hexachlorobenzene, Agent Orange, and brominated flame-retardants) since these chemicals can be metabolized in vivo ${ }^{3-11,42-45}$ or oxidized to tetra-, di-, or mono-XQ. Our findings showed that $\mathrm{XQ}$ may interact with $\mathrm{ROOH}$ and cause deleterious effects via facilitated generation of alkoxyl/ketoxy radicals and/or HNE and hence elevated damage to macromolecules.

It should be emphasized that several issues need to be further investigated, particularly with regard to their biological relevance. For instance, how does the reaction of $\mathrm{XQ} / \mathrm{ROOH}$ compare kinetically with reactions with other good nucleophiles like glutathione present at high concentrations in vivo? Could the ketoxy radical be observed in cells or in an animal model? Could the suggested enoxy radical and quinone-peroxide intermediates be observed by a freeze-quenching technique? Could the new ketoxy radical react with macromolecules such as DNA, protein, and lipids?

\section{AUTHOR INFORMATION}

Corresponding Author

*E-mail: bzhu@rcees.ac.cn.

Author Contributions

${ }^{\S}$ C.-H.H. and F.-R.R. contributed equally to this work.

Funding

This study was supported by the SPRP CAS (XDB01020300); NSFC (21237005, 21321004, 21477139, 21477139, and 21407163); and PFSC (2014M561078).

Notes

The authors declare no competing financial interest.

\section{ABBREVIATIONS}

$\mathrm{XQ}$ halogenated quinones; $\mathrm{ROOH}$, organic hydroperoxides; $\mathrm{DCBQ}$ 2,5-dichloro-1,4-benzoquinone; $t$ - $\mathrm{BuOOH}$, tert-butylhydroperoxide; $t$ - $\mathrm{BuO}^{\bullet}$, $t$-butoxyl radicals; $\mathrm{CBQ}-\mathrm{O}^{\bullet}, 2$ 2-chloro-5hydroxy-1,4-benzoquinone radical; ${ }^{\circ} \mathrm{CBQ}=\mathrm{O}$, carbon-centered quinone ketoxy radical

\section{REFERENCES}

(1) Bolton, J. L., Trush, M. A., Penning, T. M., Dryhurst, G., and Monks, T. J. (2000) Role of quinones in toxicology. Chem. Res. Toxicol. $13,135-160$.

(2) Song, Y., Wagner, B. A., Witmer, J. R., Lehmler, H. J., and Buettner, G. R. (2009) Nonenzymatic displacement of chlorine and formation of free radicals upon the reaction of glutathione with PCB quinones. Proc. Natl. Acad. Sci. U.S.A. 106, 9725-9730.

(3) Zhu, B. Z., and Shan, G. Q. (2009) Potential mechanism for pentachlorophenol-induced carcinogenicity: a novel mechanism for metal-independent production of hydroxyl radicals. Chem. Res. Toxicol. 22, 969-977.

(4) Meunier, B. (2002) Catalytic degradation of chlorinated phenols. Science 296, 270-271.

(5) Gupta, S. S., Stadler, M., Noser, C. A., Ghosh, A., Steinhoff, B., Lenoir, D., Horwitz, C. P., Schramm, K. W., and Collins, T. J. (2002) Rapid total destruction of chlorophenols by activated hydrogen peroxide. Science 296, 326-328.

(6) Sorokin, A., Meunier, B., and Seris, J. L. (1995) Efficient oxidative dechlorination and aromatic ring cleavage of chlorinated phenols catalyzed by iron sulfophthalocyanine. Science 268, 1163-1166.

(7) Zhao, Y. L., Qin, F., Boyd, J. M., Anichina, J., and Li, X. F. (2010) Characterization and determination of chloro- and bromo-benzoquinones as new chlorination disinfection byproducts in drinking water. Anal. Chem. 82, 4599-4605. 
(8) Qin, F., Zhao, Y. Y., Zhao, Y. L., Boyd, J. M., Zhou, W. J., and Li, X. F. (2010) A toxic disinfection by-product, 2,6-dichloro-1,4-benzoquinone, identified in drinking water. Angew. Chem., Int. Ed. 49, 790-792.

(9) Chignell, C. F., Han, S. K., Moulthys-Mickalad, A., Sik, R. H., Stadler, K., and Kadiiska, M. B. (2008) EPR studies of in vivo radical production by $3,3^{\prime}, 5,5^{\prime}$-tetrabromobisphenol A (TBBPA) in the Sprague-Dawley rat. Toxicol. Appl. Pharmacol. 230, 17-22.

(10) Teuten, E. L., Xu, L., and Reddy, C. M. (2005) Two abundant bioaccumulated halogenated compounds are natural products. Science 307, 917-920.

(11) Kelly, B. C., Ikonomou, M. G., Blair, J. D., Morin, A. E., and Gobas, F. A. P. C. (2007) Food web-specific biomagnification of persistent organic pollutants. Science 317, 236-239.

(12) Halliwell, B., and Gutteridge, J. (2007) Free Radicals in Biology and Medicine; Oxford University Press, Oxford, U.K.

(13) Marnett, L. J. (2000) Oxyradicals and DNA damage. Carcinogenesis $21,361-370$.

(14) Zhu, B. Z., Kitrossky, N., and Chevion, M. (2000) Evidence for production of hydroxyl radicals by pentachlorophenol metabolites and hydrogen peroxide: A metal-independent organic Fenton reaction. Biochem. Biophys. Res. Commun. 270, 942-946.

(15) Zhu, B. Z., Zhao, H. T., Kalyanaraman, B., and Frei, B. (2002) Metal-independent production of hydroxyl radicals by halogenated quinones and hydrogen peroxide: An ESR spin trapping study. Free Radical Biol. Med. 32, 465-473.

(16) Zhu, B. Z., Kalyanaraman, B., and Jiang, G. B. (2007) Molecular mechanism for metal-independent production of hydroxyl radicals by hydrogen peroxide and halogenated quinones. Proc. Natl. Acad. Sci. U.S.A. 104, 17575-17578.

(17) Zhu, B. Z., Zhu, J. G., Mao, L., Kalyanaraman, B., and Shan, G. Q. (2010) Detoxifying carcinogenic polyhalogenated quinones by hydroxamic acids via an unusual double Lossen rearrangement mechanism. Proc. Natl. Acad. Sci. U.S.A. 107, 20686-20690.

(18) Zhu, B. Z., Mao, L., Huang, C. H., Qin, H., Fan, R. M., Kalyanaraman, B., and Zhu, J. G. (2012) Unprecedented hydroxyl radical-dependent two-step chemiluminescence production by polyhalogenated quinoid carcinogens and $\mathrm{H}_{2} \mathrm{O}_{2}$. Proc. Natl. Acad. Sci. U.S.A. 109, 16046-16051.

(19) Yin, R. C., Zhang, D. P., Song, Y. L., Zhu, B. Z., and Wang, H. L. (2013) Potent DNA damage by polyhalogenated quinones and $\mathrm{H}_{2} \mathrm{O}_{2}$ via a metal-independent and Intercalation-enhanced oxidation mechanism. Sci. Rep. 3, 1269.

(20) Jia, S. P., Zhu, B. Z., and Guo, L. H. (2010) Detection and mechanistic investigation of halogenated benzoquinone induced DNA damage by photoelectrochemical DNA sensor. Anal. Bioanal. Chem. 397, 2395-2400.

(21) Shao, J., Huang, C. H., Kalyanaraman, B., and Zhu, B. Z. (2013) Potent methyl oxidation of 5-methyl-2 '-deoxycytidine by halogenated quinoid carcinogens and hydrogen peroxide via a metal-independent mechanism. Free Radical Biol. Med. 60, 177-182.

(22) Zhu, B. Z., Zhao, H. T., Kalyanaraman, B., Liu, J., Shan, G. Q., Du, Y. G., and Frei, B. (2007) Mechanism of metal-independent decomposition of organic hydroperoxides and formation of alkoxyl radicals by halogenated quinones. Proc. Natl. Acad. Sci. U.S.A. 104, 3698-3702.

(23) Mohindru, A., Fisher, J. M., and Rabinovitz, M. (1983) Bathocuproine sulphonate: a tissue culture-compatible indicator of copper-mediated toxicity. Nature 303, 64-65.

(24) Graf, E., Mahoney, J. R., Bryant, R. G., and Eaton, J. W. (1984) Iron-catalyzed hydroxyl radical formation. Stringent requirement for free iron coordination site. J. Biol. Chem. 259, 3620-3624.

(25) Dean, R. T., and Nicholson, P. (1994) The action of nine chelators on iron-dependent radical damage. Free Radical Res. 20, 83101.

(26) Sarr, D. H., Kazunga, C., Charles, M. J., Pavlovich, J. G., and Aitken, M. D. (1995) Decomposition of tetrachloro-1,4-benzoquinone (P-chloranil) in aqueous solution. Environ. Sci. Technol. 29, 2735-2740. (27) Zhu, B. Z., Shan, G. Q., Huang, C. H., Kalyanaraman, B., Mao, L., and Du, Y. G. (2009) Metal-independent decomposition of hydro- peroxides by halogenated quinones: Detection and identification of a quinone ketoxy radical. Proc. Natl. Acad. Sci. U.S.A. 106, 11466-11471.

(28) Laude, D. A. (1997) Electrospray Ionization/Fourier Transform Ion Cyclotron Resonance Mass Spectrometry, Electrospray Ionization Mass Spectrometry: Fundamentals, Instrumentation, and Applications, John Wiley and Sons, New York.

(29) Cui, L., Isbell, M. A., Chawengsub, Y., Falck, J. R., Campbell, W. B., and Nithipatikom, K. (2008) Structural characterization of monohydroxyeicosatetraenoic acids and dihydroxy- and trihydroxyeicosatrienoic acids by ESI-FTICR. J. Am. Soc. Mass Spectrom. 19, 569585 .

(30) Li, A. S. W., and Chignell, C. F. (1991) The $\mathrm{NoH}$ value in EPR spin trapping: a new parameter for the identification of 5,5-dimethyl-1pyrroline- $\mathrm{N}$-oxide spin adducts. J. Biochem. Biophys. Methods 22, 83-87.

(31) Huang, C. H., Shan, G. Q., Mao, L., Kalyanaraman, B., Qin, H., Ren, F. R., and Zhu, B. Z. (2013) The first purification and unequivocal characterization of the radical form of the carbon-centered quinone ketoxy radical adduct. Chem. Commun. 49, 6436-6438.

(32) Zhao, H. T., Joseph, J., Zhang, H., Karoui, H., and Kalyanaraman, B. (2001) Synthesis and biochemical applications of a solid cyclic nitrone spin trap: A relatively superior trap for detecting superoxide anions and glutathiyl radicals. Free Radical Biol. Med. 31, 599-606.

(33) Yin, H. Y., Xu, L. B., and Porter, N. A. (2011) Free radical lipid peroxidation: Mechanisms and analysis. Chem. Rev. 111, 5944-5972.

(34) Niki, E. (2009) Lipid peroxidation: Physiological levels and dual biological effects. Free Radical Biol. Med. 47, 469-484.

(35) Blair, I. A. (2008) DNA adducts with lipid peroxidation products. J. Biol. Chem. 283, 15545-15549.

(36) Lee, S. H., Oe, T., and Blair, I. A. (2001) Vitamin C-induced decomposition of lipid hydroperoxides to endogenous genotoxins. Science 292, 2083-2086.

(37) Qian, S. Y., Yue, G. H., Tomer, K. B., and Mason, R. P. (2003) Identification of all classes of spin-trapped carbon-centered radicals in soybean lipoxygenase-dependent lipid peroxidations of omega-6 polyunsaturated fatty acids via LC/ESR, LC/MS, and tandem MS. Free Radical Biol. Med. 34, 1017-1028.

(38) Iwahashi, H., Hirai, T., and Kumamoto, K. (2006) High performance liquid chromatography/electron spin resonance/mass spectrometry analyses of radicals formed in an anaerobic reaction of 9- (or 13-) hydroperoxide octadecadienoic acids with ferrous ions. J. Chromatogr., A 1132, 67-75.

(39) Spiteller, P., Kern, W., Reiner, J., and Spiteller, G. (2001) Aldehydic lipid peroxidation products derived from linoleic acid. Biochim. Biophys. Acta 1531, 188-208.

(40) Schneider, C., Porter, N. A., and Brash, A. R. (2008) Routes to 4hydroxynonenal: Fundamental issues in the mechanisms of lipid peroxidation. J. Biol. Chem. 283, 15539-15543.

(41) Qin, H., Huang, C. H., Mao, L., Xia, H. Y., Kalyanaraman, B., Shao, J., Shan, G. Q., and Zhu, B. Z. (2013) Molecular mechanism of metalindependent decomposition of lipid hydroperoxide 13-HPODE by halogenated quinoid carcinogens. Free Radical Biol. Med. 63, 459-466.

(42) Haugland, R. A., Schlemm, D. J., Lyons, R. P., Sferra, P. R., and Chakrabarty, A. M. (1990) Degradation of the chlorinated phenoxyacetate herbicides 2,4-dichlorophenoxyacetic acid and 2,4,5-trichlorophenoxyacetic acid by pure and mixed bacterial cultures. Appl. Environ. Microbiol. 56, 1357-1362.

(43) Koss, G., Losekam, M., Seidel, J., Steinbach, K., and Koransky, W. (1987) Inhibitory effect of tetrachloro-p-hydroquinone and other metabolites of hexachlorobenzene on hepatic uroporphyrinogen decarboxylase activity with reference to the role of glutathione. Ann. N.Y. Acad. Sci. 514, 148-159.

(44) Vanommen, B., Adang, A. E. P., Brader, L., Posthumus, M. A., Muller, F., and Vanbladeren, P. J. (1986) The microsomal metabolism of hexachlorobenzene. Origin of the covalent binding to protein. Biochem. Pharmacol. 35, 3233-3238.

(45) Czaplicka, M. (2004) Sources and transformations of chlorophenols in the natural environment. Sci. Total Environ. 322, $21-39$. 